\title{
SEISMIC AND WIND PERFORMANCE OF MULTI-STOREYED BUILDING WITH PLAN AND VERTICAL IRREGULARITIES
}

\author{
BILAL AHMAD LONE ${ }^{1}$, JAGDISH CHAND ${ }^{2} \&$ DR. MOHIT BHANDARI ${ }^{3}$ \\ ${ }^{I} M$ Tech Scholar, Chandigarh University, Punjab, India \\ ${ }^{2}$ Associate Professor, Chandigarh University, Punjab, India \\ ${ }^{3}$ Assistant Professor, Chandigarh University, Punjab, India
}

\begin{abstract}
It is a big challenge that the tall buildings must withstand the various forces acting from different directions and aspects such as seismic and wind forces while designing the tall structures it is mandatory to deeply understand the seismic and wind behaviour of multi-storeyed buildings. In this study we are concerned to determine and analyse the seismic and wind behaviour of high-rise buildings some of which were regular and other had irregularities in them in their plan and elevations. Three G+30 storied buildings were considered which were situated in seismic Zone-V and analysis were carried out using response spectrum method as per IS 1893- 2016 on ETABS software. Each building is subjected to wind load at different terrain categories to examine its effects at different slopes as per IS 875 Part 32015 .Various parameters like Auto lateral load, maximum storey displacement, maximum storey drift, over-turning moment, storey shear and time period were considered in this study. It is concluded that vertical irregular building in terrain category-4 with ground slope less than 3 degree's provides greater resistance against both seismic and wind loading among all buildings.

KEYWORDS: Wind Performance
\end{abstract}

Received: Jun 09, 2020; Accepted: Jun 29, 2020; Published: Aug 06, 2020; Paper Id.: IJMPERDJUN2020642

\section{INTRODUCTION}

Earthquake and wind have been among the most dangerous natural hazards causing significant loss of life and livelihood. An earthquake is a tremor of ground vibration induced by the sudden release of energy in the earth's lithosphere. This energy comes primarily from stress generated by tectonic activity and the interior of the earth through which there is friction between the crust and the earth's inner touch. In India, earthquakes of high frequency have occurred throughout history with a very high magnitude of over 8. In Dec 24, 2004, one of the deadly Indian earthquake occurred with magnitude 9.1-9.3 having epicentre west coast of Sumatra. On January 15, 1993, another Bihar and Nepal occurred with magnitude 8.7 having an epicentre south of the Everest range. The Kashmir earthquake occurred on 8 October 2005 with an epicentre Muzaffarabad of magnitude 7.6, Pakistan administered Kashmir. Assam earthquake occurred on August 15, 1950 with epicentre Rima, Tibet, having magnitude 8.6. Another of India's devastating earthquakes is kanga earthquake with magnitude 7.8 occurs in April 4, 1905.

Ground motions generating the earthquake are the most devastating motions resulting in loss of life and livelihood. Earthquake damage is caused not only by vibrations or ground motion but also by chain effects such as landslides, flooding, and fires. The structure must be designed with greater stability to withstand extreme and severe ground vibrations based on site position and structural significance. Engineers are not going to design fully earthquake resistant building because earthquake has dynamic nature and it occurs randomly with varying intensity 
and magnitude. The engineers are not trying to create fully earthquake resistant structure that would not get destroyed even by occurrence of rare earthquakes with his intensity but for those earthquakes which have very high intensity these type of structures would be very strong and therefore too costly instead the purpose of engineers is to construct an earthquake resistant building these type of buildings have very high resisting capacity during ground shaking though they could be seriously damaged but will not collapse when hit by high intensity earthquake, therefore the protection of citizens and materials in earthquake resistant buildings is ensured and provides protection for failure of structure and prevent disaster this is the main function of all earthquakes codes in the whole world.

Wind load and seismic load play a key role in the design of high rise structures, since the remaining all other loads vary in a very small margin, this study deals with the seismic and wind load effect of symmetrical and asymmetrical high rise buildings. If a structure is designed with high wind resistance the structure becomes more expensive. In order to maintain a proper balance between economy and safety, it is crucially important to have a deep understanding of the relationship between the behaviour of buildings subjected to seismic and wind forces. Wind usually plays a significant role in the design of tall buildings. Forces and moments are produced by wind and these forces and moments are applied to the structure and the cladding and wind pressure around the building is generated

Wind has no pre-defined way it moves randomly with specific speed and when it hits the structure pressure is applied on the outer surfaces of structure by which wind forces is generated, wind forces are a part of structural height, surrounding terrains and topographical behaviour (slopes, hills of trees etc.) and velocity. Xinzhong Chen and Ahsan Kareem (2005) Performed equivalent static and dynamic wind analysis of buildings considering three dimensional modes". They conducted study on multi-storey buildings having complex geometry to determine the dynamic responses of buildings and modelled these buildings using equivalent static and dynamic method. It has been concluded that the lateral loads such as dynamic wind load with varying nature has been performed on building surfaces using synchronous scanning at different pressure units and it is necessary to consider effects of wind loads along different direction and model coupling from response of model components. Chintanapakdee and Anil K. Chopra (2004) conducted study on seismic behaviour of irregular buildings considering vertical irregularity. They studied seismic capacity of regular and irregular structures using two types of analysis one non-linear time history and second pushover analysis, 12 storey building were considered for design having strong columns and weak beams and three type of irregularities are taken such as strength, stiffness and combined strength and stiffness to determine the soft storey and weak storey effect in each analysis. It has been found that the effect were more in combined strength and stiffness irregularity among all of irregularities, storey drift is greater in buildings having soft storey and less in buildings having strong or stiff storey. Jack P and Luis F (1986) conducted study on seismic behaviour of irregular buildings considering different analysis methods. They studied that earthquake response of two wall frame structures subjected to earthquake forces due to ground motion shaking. The structural response are measured and compared with other responses measured from response history analysis, inelastic static analysis, and elastic static analysis. It has been concluded that dynamic methods gives better results than static methods. 


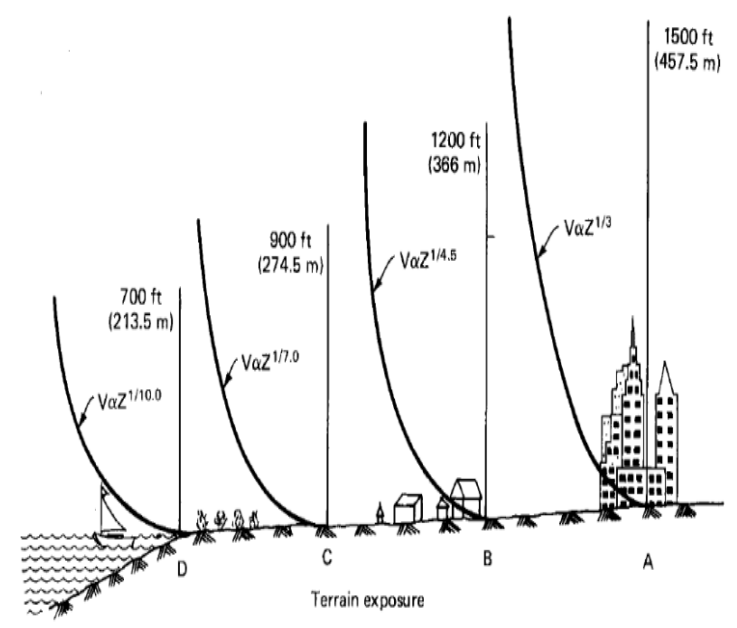

Figure 1: Variation of Wind with Height.

\section{Topography Factor k3 - (According to IS 875 Part 3)}

The topography factor's effect varies from 1 to 1.36 , basically depending on the ground slope. If the slope is less than $3^{\circ}$ the topography factor value $\mathrm{k} 3$ is taken directly as 1 according to part 3 of IS 875 . If the slope exceeds $17^{\circ}$, the topography factor value is taken directly as 1.36 as per part 3 of IS 875 . The values from 1 to 1.36 are calculated in IS 875 part from Appendix C

\section{Calculation for Topographic Factor at $10^{\circ}$ and $15^{\circ}$ Slopes}

The effect of topography factor is taken 1.5Le for upwind and 2.5Le for downwind. Where Le is the effective length of hill, it depends upon the slope of hill as shown below

Table 1

\begin{tabular}{|c|c|}
\hline Slope & Le \\
\hline $3^{\circ}<\theta<17^{\circ}$ & $\mathrm{L}$ \\
\hline$>17^{\circ}$ & $\mathrm{Z} / 0.3$ \\
\hline
\end{tabular}

$\mathrm{L}=$ Actual length of upwind slope along wind direction.

$\mathrm{Z}=$ Effective height of hill.

Topography factor for $10^{\circ}$ slope

$\mathrm{K}_{3}=1+\mathrm{C} . \mathrm{S}$

Table 2

\begin{tabular}{|c|c|}
\hline Slope & $\mathbf{C}$ \\
\hline $3^{\circ}<\theta<17^{\circ}$ & $1.2(\mathrm{Z} / \mathrm{L})$ \\
\hline$>17^{\circ}$ & 0.36 \\
\hline
\end{tabular}


S, is calculated from fig. 16 and fig 17 of IS 875 part 3

Location of hill -Srinagar

Height of hill $-900 \mathrm{~m}$

Location from crest $-200 \mathrm{~m}$

$\tan \theta=\frac{z}{L}$

$\tan 10^{\circ}=\frac{900}{L}$

$L=5104.15=L e$

Now,

$$
\begin{aligned}
& C=1.2\left(\frac{900}{5104.15}\right) \\
& C=0.21
\end{aligned}
$$

Now value of $\mathrm{S}$ is calculated from $\frac{X}{L \oplus}$ and $\frac{H}{L \theta}$ as shown in fig 16 in Appendix C of IS 875 Part 3.

$$
\begin{aligned}
& \frac{900}{5104.15}=\frac{H}{(5104.15-200)} \\
& H=864.73 m
\end{aligned}
$$

Now,

$$
\begin{aligned}
& \frac{H}{L g}=\frac{864.73}{5104.15}=0.169 \\
& \mathrm{~S}=0.7 \\
& K_{3}=1+0.21 \times 0.7=1.15
\end{aligned}
$$

Same procedure is for calculating topography factor at slope $15^{\circ}$

In the past, the traditional approach for constructing tall buildings was in the form of a rectangular shape, but in practice there is now much more complex geometry. High rise structures include four major factors such as rigidity, ductility, normal and simple structure, and sufficient lateral force. Symmetrical geometry structures in plan and elevation have less damage impact than irregular configuration.

The structural configuration is defined in terms of shape, size and centre of mass stiffness in the structure according to IS1893-2016.A building should be irregular if it is not symmetrical and has discontinuity in geometry, mass or load, these irregularities create problems in force action and distribution of stress. Analysis of the structure plays a key role in determining the behaviour of the structures subject to certain actions, dynamic loads include Wind, waves, traffic, earthquake and blasts, dynamic loads reduces the structural efficiency of structure because structural forces get increased by which structure will collapse eventually. 


\section{TYPES OF IRREGULARITIES}

\section{Plan Irregularity; (Its Types and Description)}

- Torsional Irregularity -

To be studied when floor diaphragms are rigid in their own plans which are connected with the vertical structure elements that resist the lateral load action. Torsional irregularity occurs at that point when max storey drift as compared with design eccentricity along one end of structure is more than 1.2 times the average storey drift with two ends of structure.

- Re-entrant Corners -

A structure is said to have a re-entrant corner in any plan direction when its structural configuration in plan has a projection of size greater than $15 \%$ of its overall plan dimension in that direction.

\section{Vertical Irregularity; (its types and description)}

- Stiffness Irregularity -Extreme soft storey

Extreme soft storey is defined when lateral stiffness is less than $60 \%$ of the above storey or less than the $70 \%$ of the average stiffness of the three storeys above

- Stiffness irregularity - (soft storey)

Soft storey is defined when lateral stiffness is less than $80 \%$ of the above three storeys.

- Mass irregularity -

When seismic weight of any storey is more than the $200 \%$ of its adjacent storey.

- Vertical geometric -

This irregularity exists when the horizontal dimension of the lateral force resisting system in any storey is more than $120 \%$ to the adjacent storey.

- In plane discontinuity in vertical elements resisting lateral fore -

In plane discontinuity in vertical elements which are resisting lateral force exists in a structure when in plane offset of the lateral force resisting elements is greater than $20 \%$ of its plan length of their structural elements.

- Strength irregularity - (weak storey)

Weak story is defined when lateral strength is less than $80 \%$ of the storey above Types of Vertical Irregularities (according to IS 1893-2016) 


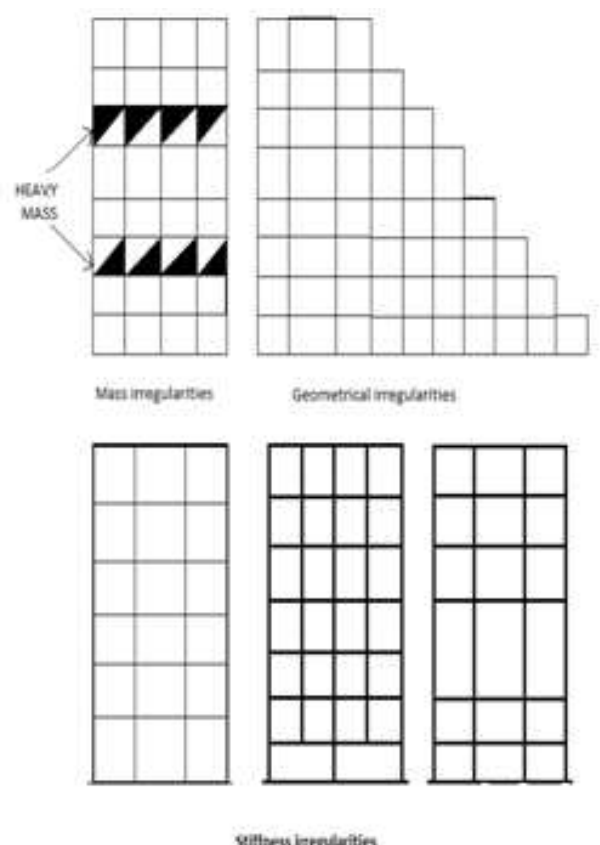

Figure 2

\section{OBJECTIVES}

- Comparing seismic capacity of moment resisting frame structure with symmetrical (rectangular) and asymmetrical earthquake zone-V plan.

- Comparing the wind resistance of a symmetrical building, irregular plan building and vertical irregular building

- The design models of buildings with symmetrical and asymmetrical geometry will be compared by changing type of terrain category, and topography factor to provide better information about the response of the system.

- To find out which building type will be more effective against lateral loads on each terrain category.

- To develop a most suitable model out of wind and seismic analysis, each for regular and irregular type of structures will perform well in Zone V.

\section{MODELLING AND ANALYSIS}

In fact, given the improvements in earthquake engineering over the last three decades, there are still many problems. A construction strategy for buildings plays a significant role in combating lateral forces and the distribution of earthquake forces. Past work indicates that buildings with unsymmetrical planes are more susceptible to earthquake than those with symmetric plans. Therefore, symmetry on both axes should be considered not only for buildings but also for the structural elements.In this research three $G+30$ storeyed buildings of same plan dimensions $52 m x 44 m$ were considered for regular building, irregular plan building and vertical irregular buildings. These buildings are modelled and analysed in different terrains using ETABS software. All the Moment Resisting Frame elements are designed as per IS 456-2000. Wind and earthquake loads are defined as per IS 875 part-3, and IS 1893-2016 respectively. Table (1) shows building description and Table (2) shows terrain details for modelling and analysis of buildings. 


\section{BUILDING SPECIFICATION}

Geometrical description and Material Properties of Buildings

Table 3

\begin{tabular}{|l|c|}
\hline \multicolumn{1}{|c|}{ Type of Structure } & Moment Resisting Frame Structure \\
\hline Plan size & $52 m \times 44 m$ \\
\hline No. of storey & $(G+30)$ \\
\hline Floor to floor height & $3.5 m$ \\
\hline Grade of concrete & M35 for columns, M30 for beams \\
\hline Grade of steel & $650 \mathrm{~mm} \times \mathbf{m} \times \mathbf{4 0 0} \mathrm{mm}$ \\
\hline Beam size & $900 \mathrm{~mm} x 700 \mathrm{~mm}$ \\
\hline Column size & $150 \mathrm{~mm}$ \\
\hline Slab thickness & $4 m$ \\
\hline Spacing in y-dir. & $4 m$ \\
\hline Spacing in x-dir. & $2 \mathrm{kN} / \mathrm{m}^{2}$ \\
\hline Dead load & $3 \mathrm{kN} / \mathrm{m}^{2}$ \\
\hline Live load & $15 \mathrm{kN} / \mathrm{m}^{2}$ \\
\hline Wall load & $\mathrm{V}$ \\
\hline Seismic zone & 1.2 \\
\hline Importance factor & 5 \\
\hline Response reduction factor & $\mathrm{Medium}$ \\
\hline Type of soil & \\
\hline
\end{tabular}

\section{TERRAIN DETAILS}

Table 4

\begin{tabular}{|c|c|c|}
\hline Terrain Category & Slope & Topography Factor \\
\hline 1 & $10^{\circ}$ & 1.15 \\
\hline 2 & $15^{\circ}$ & 1.24 \\
\hline 3 & $20^{\circ}$ & 1.36 \\
\hline 4 & $3^{\circ}$ & 1 \\
\hline
\end{tabular}

\section{BUILDING PLANS AND MODELS}

In the present study three building models are considered for analysis (i) Building having symmetrical plan (SB-R $)_{1}$, (ii) Irregular Plan building (IPB-R $)$, and (iii) Vertical irregular building (VIB- $\left.{ }_{3}\right)$

Fig. 2 Shows plan and $3 D$ view of regular building $\left(\mathrm{SB}-\mathrm{R}_{1}\right)$ which is symmetrical about axis, Fig. 3 shows plan and $3 D$ view of $\mathrm{L}$ shaped building (IPB-R ${ }_{2}$ which is asymmetrical about its own axis and Fig. 4 Shows plan and $3 D$ view of vertical irregular building $\left(\mathrm{VIB}-\mathrm{R}_{3}\right)$ with set-backs at different levels. Each building is provided with $4 \mathrm{~m}$ column spacing and have same plan dimension $36 m x 44 m$. All of these are G+30 storey buildings with a floor height of $3.5 m$ each. 


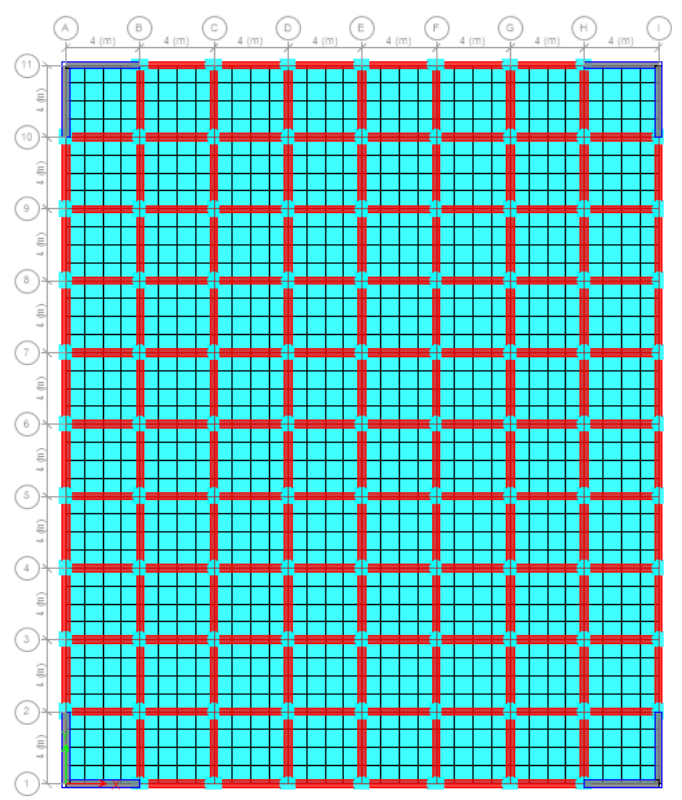

(a) Plan View

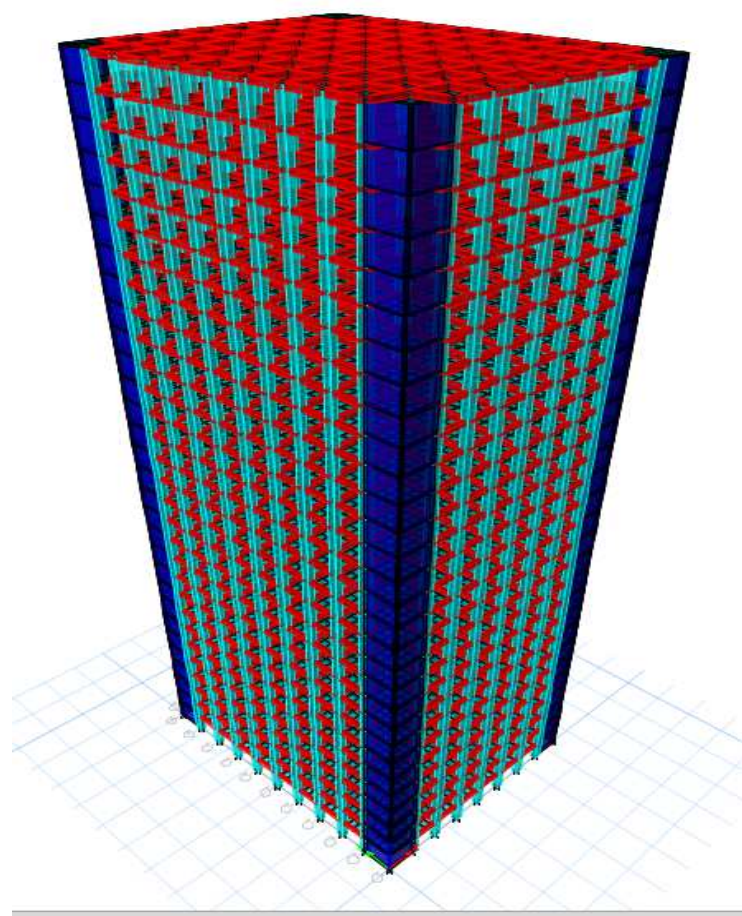

(b) 3D View

Figure 3: Plan and 3D View of Regular Building (SB). 


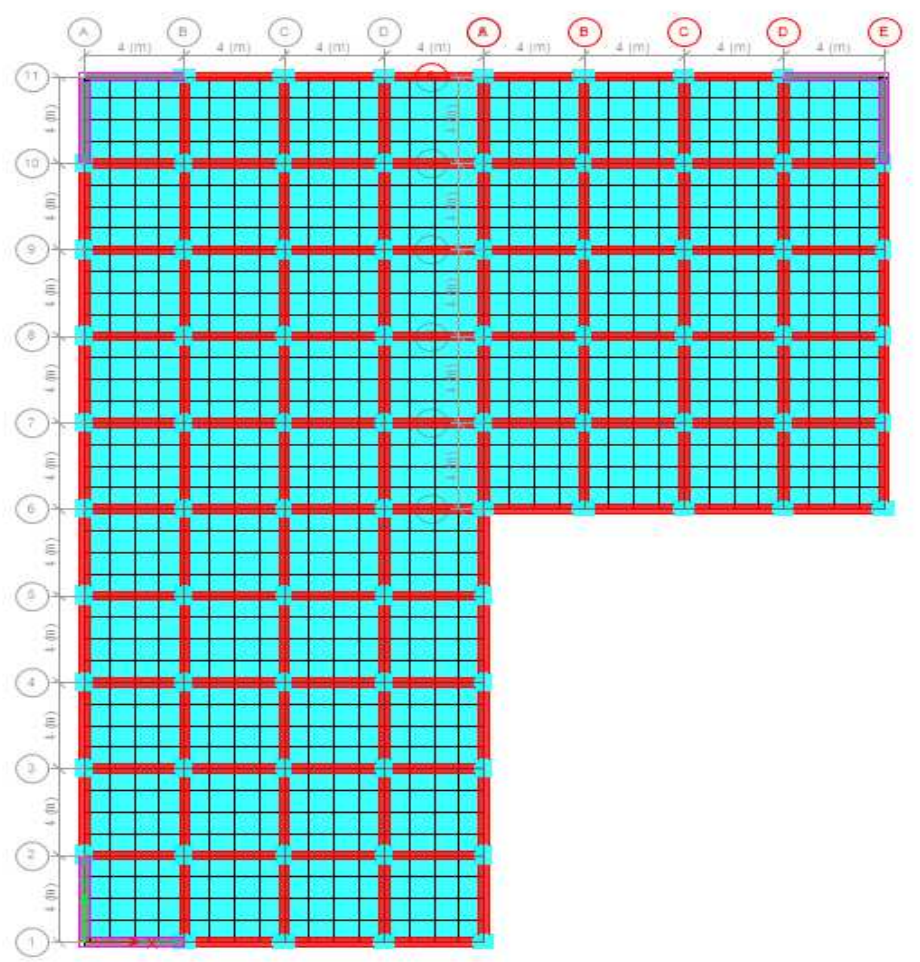

(a) Plan

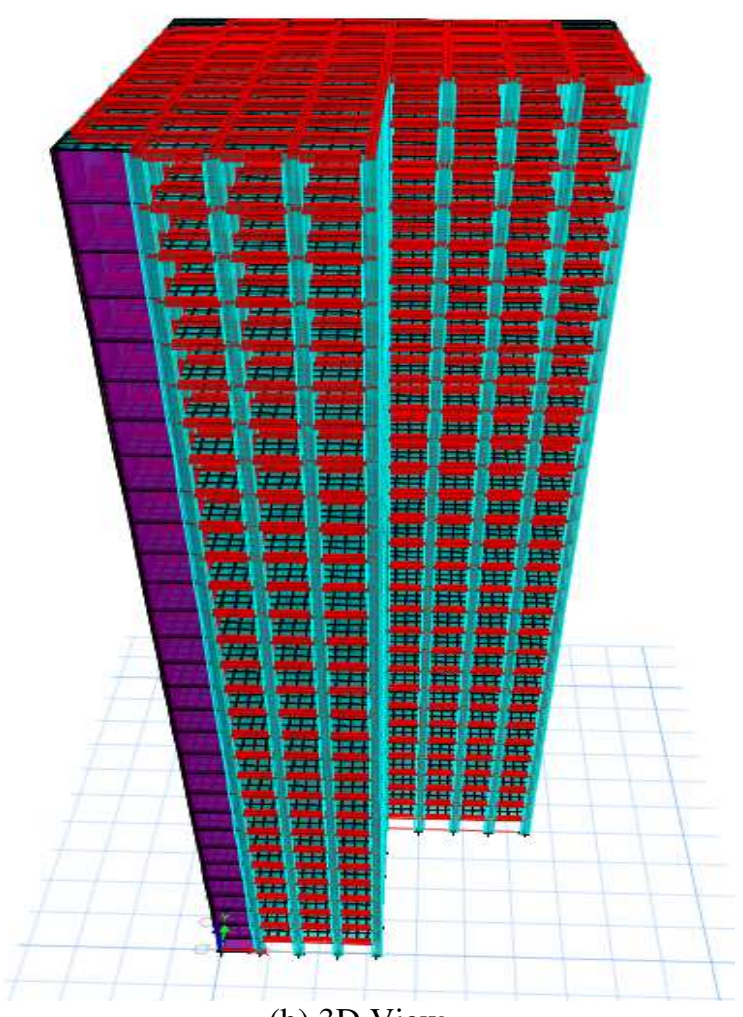

(b) 3D View

Figure 4: Plan and 3D View of Irregular Plan Building (IPB). 


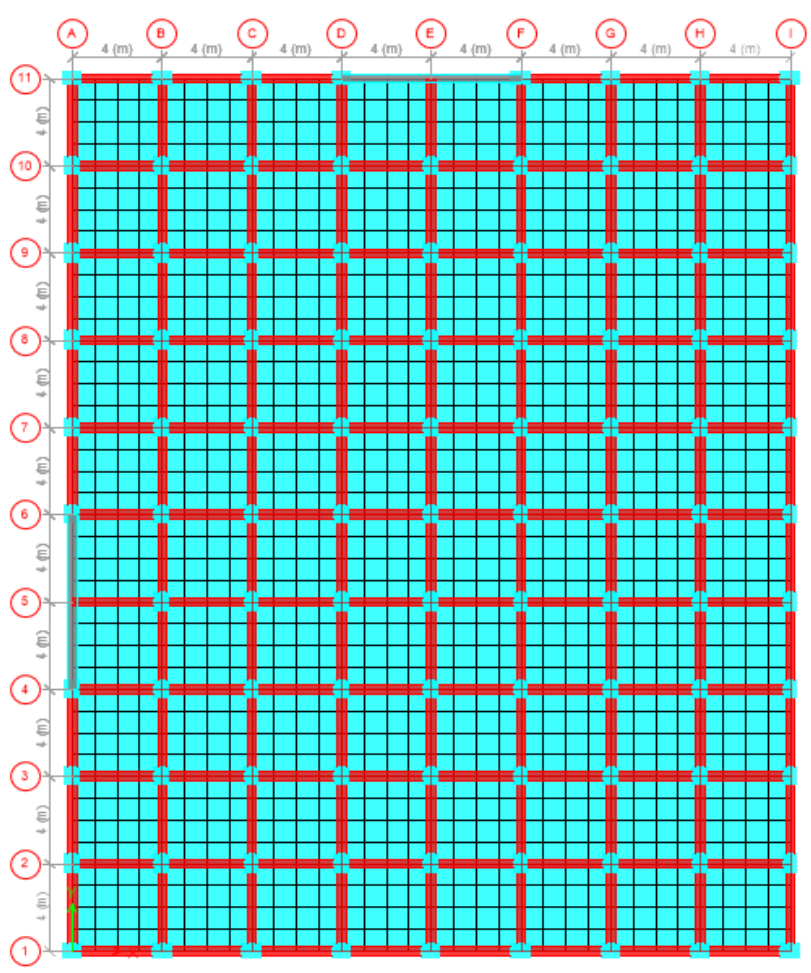

(a) Plan

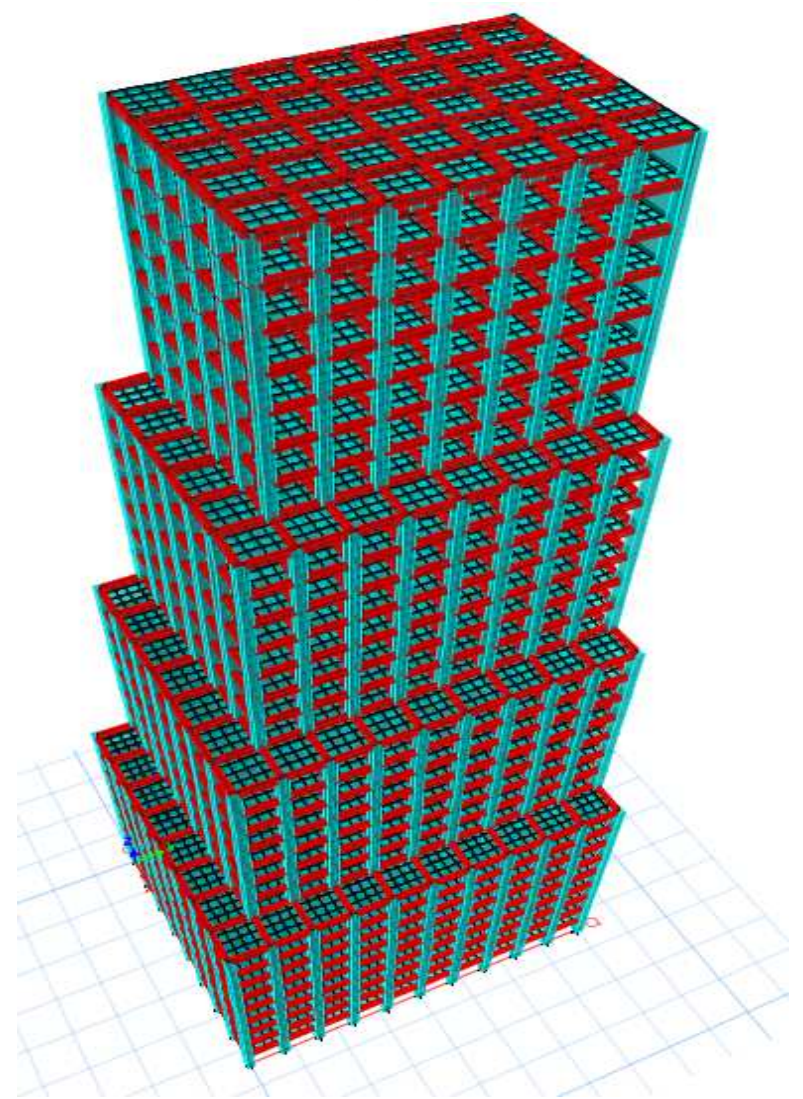

(b) 3D View

Figure 5: Plan and 3D View of Vertical Irregular Building (VIB). 


\section{RESULTS AND DISCUSSIONS}

The explanation of results carried out by seismic and wind analysis of regular and irregular buildings are presented in this section. The results of different parameters like displacement, drift, overturning moment, base shear and time period for different terrains of varying slope were presented below.

It is observed that in seismic analysis the buildings in all terrains show same variation of results. In Fig-5 the displacement of SB- $\mathrm{R}_{1}$ and VIB- $\mathrm{R}_{3}$ decreases by $31 \%$ and $22 \%$ than IPB- $\mathrm{R}_{2}$ and the drift of SB-R $\mathrm{R}_{1}$ and VIB-R $\mathrm{R}_{3}$ decreased by $28 \%$ and $16 \%$ than IPB- $\mathrm{R}_{2}$ respectively. The Overturning moment of IPB- $\mathrm{R}_{2}$ and VIB- $\mathrm{R}_{3}$ is decreased by $22 \%$ and $18 \%$ than SB- $R_{1}$ and base shear of IPB- $R_{2}$ and VIB- $R_{3}$ is decreased by $26 \%$ and $16 \%$ than SB- $R_{1}$ respectively in all terrains.

In terrain category-1 due to wind loading action the Fig-6 shows that displacement is maximum in IPB-R $\mathrm{R}_{2}$ and minimum in VIB- $R_{3}$. Displacement of $S B-R_{1}$ and VIB- $R_{3}$ is decreased by $15 \%$ and $47 \%$ than IPB- $R_{2}$ and storey drift is maximum in IPB and minimum in VIB- $R_{3}$. Drift of SB- $R_{1}$ and VIB- $R_{3}$ decreases by $16 \%$ and $49 \%$ than IPB-R Overturning moment is maximum in $S B-R_{1}$ and minimum in VIB- $R_{3}$. Overturning moment in IPB- $R_{2}$ and VIB- $R_{3}$ is decreased by $7 \%$ and $29 \%$ than SB- $\mathrm{R}_{1}$ and also base shear is maximum in SB- $\mathrm{R}_{1}$ and minimum in VIB-R $\mathrm{R}_{3}$. Base shear in IPB- $\mathrm{R}_{2}$ and VIB- $\mathrm{R}_{3}$ is decreased by $7 \%$ and $18 \%$ than $S B-\mathrm{R}_{1}$ respectively.

In terrain category-2, due to wind loading action, the Fig-7 show that displacement is maximum in IPB-R $\mathrm{R}_{2}$ and minimum in $\mathrm{SB}-\mathrm{R}_{1}$. Displacement in $\mathrm{SB}-\mathrm{R}_{1}$ and VIB- $\mathrm{R}_{3}$ is decreased by $47 \%$ and $45 \%$ than IPB- $\mathrm{R}_{2}$ and storey drift is maximum in IPB- $R_{2}$ and minimum in VIB- $R_{3}$. Drift in $S B-R_{1}$ and VIB- $R_{3}$ is decreased by

$45 \%$ and $55 \%$ than IPB- $R_{2}$. Overturning moment is maximum in IPB- $R_{2}$ and minimum in VIB- $R_{3}$. Overturning moment in SB- $\mathrm{R}_{1}$ and VIB- $\mathrm{R}_{3}$ is decreased by $6 \%$ and $24 \%$ than IPB- $\mathrm{R}_{2}$ and also base shear maximum in IPB- $\mathrm{R}_{2}$ and minimum in VIB- $\mathrm{R}_{3}$. Base shear in $S B-\mathrm{R}_{1}$ and VIB- $\mathrm{R}_{3}$ is decreased by $6 \%$ and $17 \%$ than IPB- $\mathrm{R}_{2}$ respectively.

In terrain category-3 due to wind loading action the Fig- 8 shows that displacement of SB-R $\mathrm{R}_{1}$ and VIB-R decreases by $53 \%$ and $45 \%$ than PIB- $\mathrm{R}_{2}$ and storey drift of SB-R $\mathrm{R}_{1}$ and VIB- $\mathrm{R}_{3}$ decreases by $41 \%$ and $49 \%$ respectively than IPB- $R_{2}$. Overturning moment of SB- $R_{1}$ and VIB- $R_{3}$ is decreases by $3 \%$ and $23 \%$ respectively than IPB-R 2 and also base shear of SB-R $\mathrm{R}_{1}$ and VIB-R $\mathrm{R}_{3}$ decreases by $3 \%$ and $17 \%$ respectively than IPB- $\mathrm{R}_{2}$.

In terrain category-4 due to wind loading action the Fig- 8 shows that displacement is maximum in IPB-R $\mathrm{R}_{2}$ and minimum in $S B-R_{1}$. Displacement of $S B-R_{1}$ and VIB- $R_{3}$ is decreased by $633 \%$ and $45 \%$ respectively than IPB-R $R_{2}$ and storey drift is maximum in IPB- $\mathrm{R}_{2}$ and minimum in VIB- $\mathrm{R}_{3}$. Storey drift of $\mathrm{SB}-\mathrm{R}_{1}$ and VIB-R $\mathrm{R}_{3}$ is decreased by $45 \%$ and $57 \%$ than IPB- $\mathrm{R}_{2}$. Overturning moment is maximum in IPB- $\mathrm{R}_{2}$ and minimum in VIB- $\mathrm{R}_{3}$. Overturning moment of $\mathrm{SB}-\mathrm{R}_{1}$ and VIB- $\mathrm{R}_{3}$ is decreased by $7 \%$ and $23 \%$ respectively than IPB- $\mathrm{R}_{2}$ and also base shear is maximum in SB-R and minimum in VIB- $R_{3}$. Base shear of IPB- $R_{2}$ and VIB- $R_{3}$ is decreased by $5 \%$ and $17 \%$ respectively than $S B-R_{1}$. 
Table 5: Results of Seismic Analysis of 3D Models

\begin{tabular}{|c|c|c|c|c|}
\hline Models & $\begin{array}{c}\text { Max. } \\
\text { Displacement in } \\
\boldsymbol{m m}\end{array}$ & $\begin{array}{c}\text { Maximum } \\
\text { Drift }\end{array}$ & $\begin{array}{c}\text { Max. Overturning } \\
\text { Moment } \boldsymbol{k} \boldsymbol{N}-\boldsymbol{m}\end{array}$ & $\begin{array}{c}\text { Base Shear in } \\
\boldsymbol{k} \boldsymbol{N}\end{array}$ \\
\hline $\mathrm{SB}^{\mathrm{R}} \mathrm{R}_{1}$ & 70.162 & 0.000884 & 461431.8023 & 8237.169 \\
\hline $\mathrm{IPB}_{2}$ & 97.4 & 0.00134 & 365024.0375 & 6218.059 \\
\hline VIB-R & 79.795 & 0.001149 & 373422.5902 & 6994.5419 \\
\hline
\end{tabular}

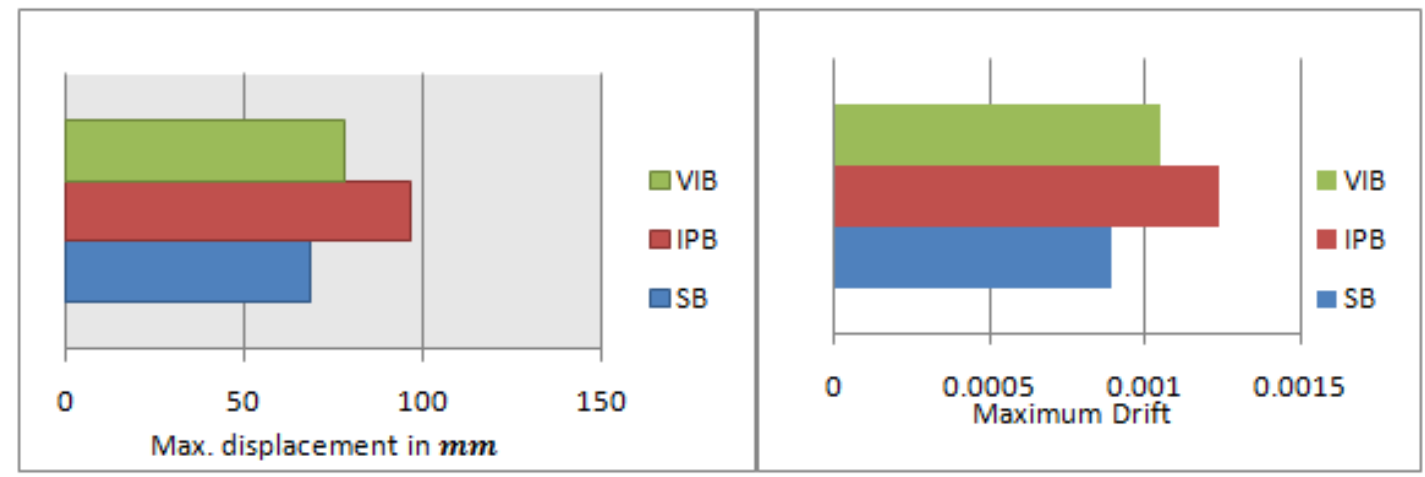

(a)

(b)

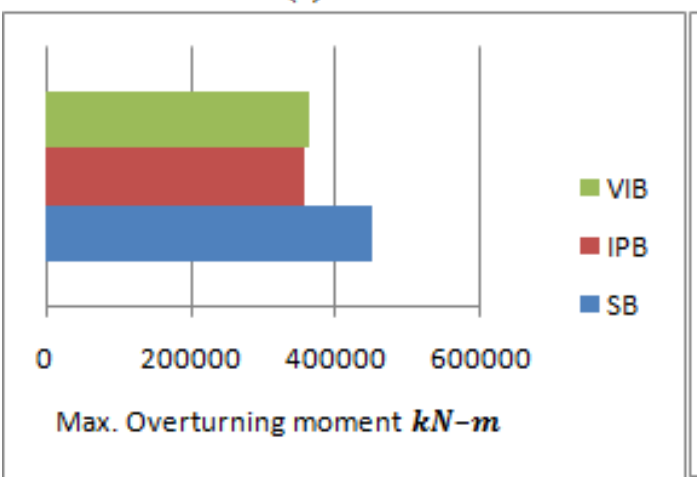

(c)

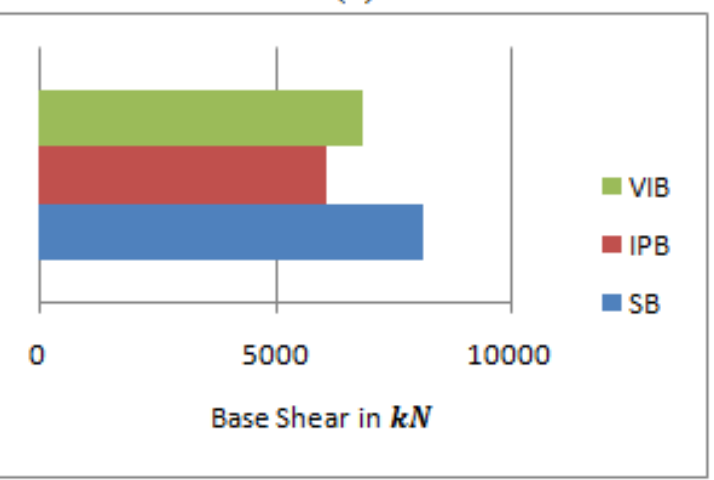

(d)

Figure 6: Shows Variation of (a) Max. Displacement (b) Max. Drift (c) Max. Overturning Moment (d) Max. Base Shear due to Seismic Analysis.

Table 6: Results of Wind Analysis in Terrain Category 1

\begin{tabular}{|c|c|c|c|c|}
\hline Models & Max. displacement in $\boldsymbol{m m}$ & Max. Drift & Max. Overturning moment $\boldsymbol{k N}-\boldsymbol{m}$ & Base Shear in $k \mathbf{N}$ \\
\hline SB-R $_{1}$ & 91.996 & 0.00134 & 603179.917 & 11361.6423 \\
\hline $\mathrm{IPB}_{2}$ & 166.644 & 0.001556 & 571886.1199 & 10793.8735 \\
\hline $\mathrm{VIB}_{2}$ & 89.193 & 0.000768 & 445833.5067 & 9076.8582 \\
\hline
\end{tabular}




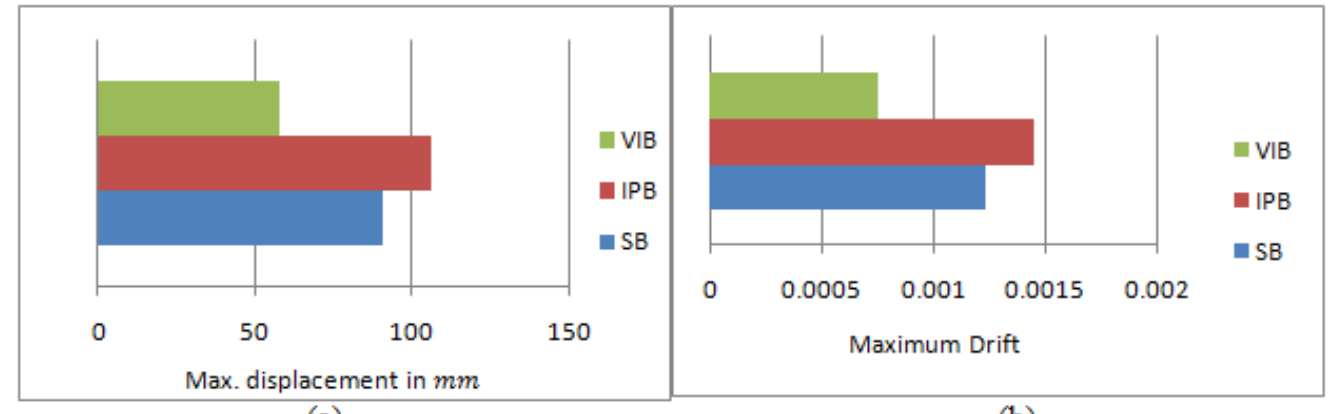

(a)

(b)

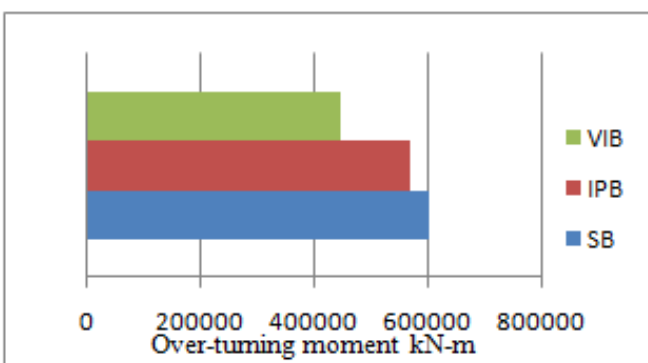

(c)

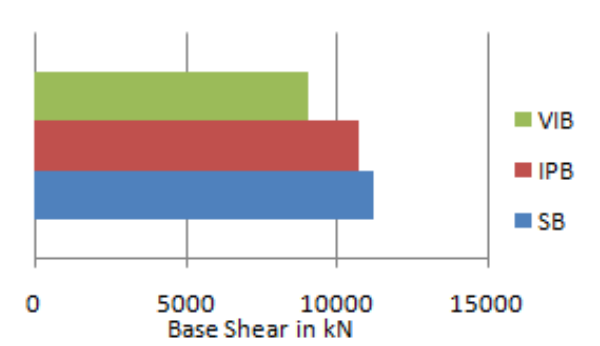

(d)

Figure 7: Shows Variation of (a) Max. Displacement (b) Max. Drift (c) Max. Overturning Moment (d) Max. Base Shear due to Wind Analysis in Terrain Category-1.

Table 7: Results of Wind Analysis in Terrain Category 2

\begin{tabular}{|c|c|c|c|c|}
\hline Models & $\begin{array}{c}\text { Max. Displacement in } \\
m m\end{array}$ & $\begin{array}{c}\text { Maximum } \\
\text { Drift }\end{array}$ & $\begin{array}{c}\text { Max. Overturning Moment } \\
\mathbf{k N}-m\end{array}$ & $\begin{array}{c}\text { Base Shear in } \\
\mathrm{kN}\end{array}$ \\
\hline $\mathrm{SB} \mathrm{R}_{1}$ & 96.646 & 0.001314 & 632961.7044 & 11347.12 \\
\hline $\mathrm{IPB}_{2}$ & 175.697 & 0.002338 & 636116.9352 & 11895.2672 \\
\hline VIB-R & 99.275 & 0.001188 & 495112.6145 & 9988.2132 \\
\hline
\end{tabular}

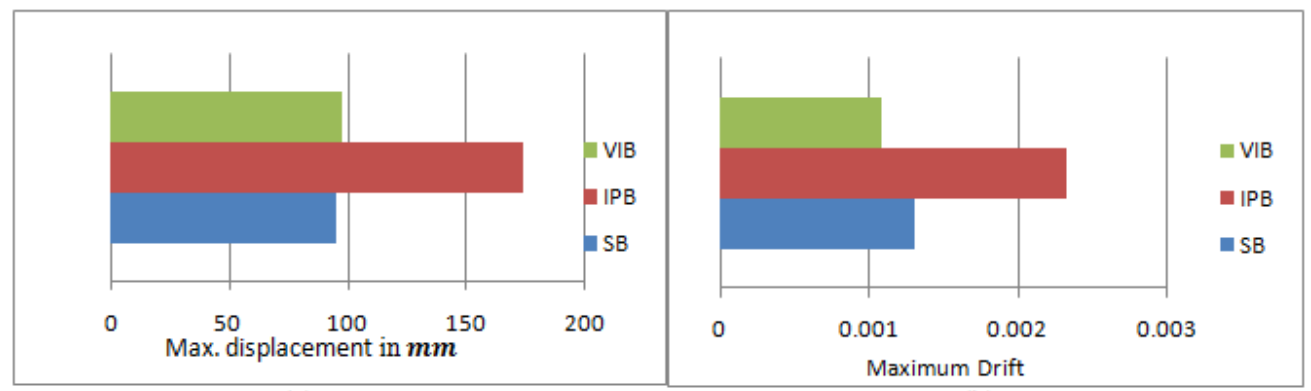

(a)

(b)

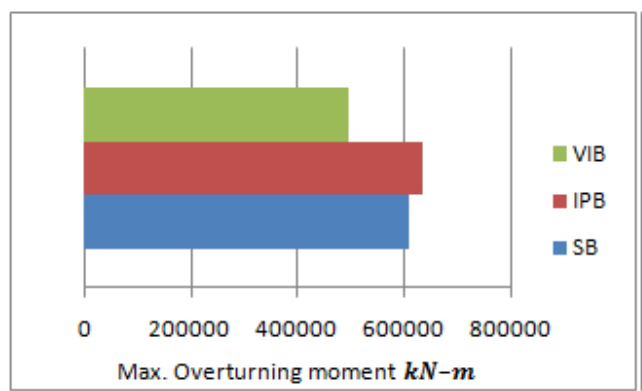

(c)

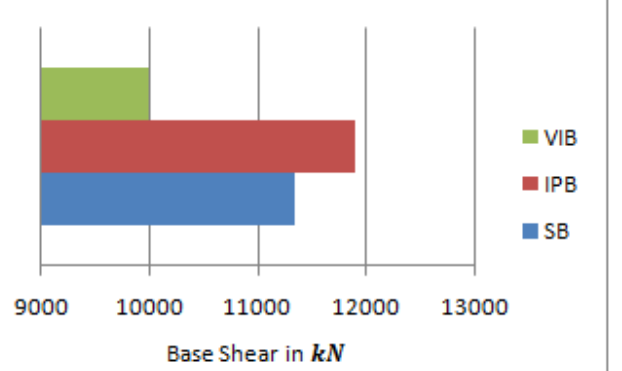

(d)

Figure 8: Shows Variation of (a) Max. Displacement (b) Max. Drift (c) Max. Overturning Moment (d) Max. Base Shear due to Wind Analysis in Terrain Category-2. 
Table 8: Results of Wind Analysis in Terrain Category 3

\begin{tabular}{|c|c|c|c|c|}
\hline Models & $\begin{array}{c}\text { Max. Displacement in } \\
m m\end{array}$ & Maximum Drift & Max. Overturning Moment $\boldsymbol{k} N-m$ & Base Shear in $k \boldsymbol{N}$ \\
\hline $\mathrm{SB}^{\mathrm{R}} \mathrm{R}_{1}$ & 97.345 & 0.001188 & 703254.504 & 12963.7158 \\
\hline $\mathrm{IPB}_{2}$ & 195.374 & 0.001899 & 706568.1662 & 13027.0717 \\
\hline $\mathrm{VIB}_{2} \mathrm{R}_{3}$ & 119.207 & 0.000946 & 548692.9536 & 10899.9173 \\
\hline
\end{tabular}

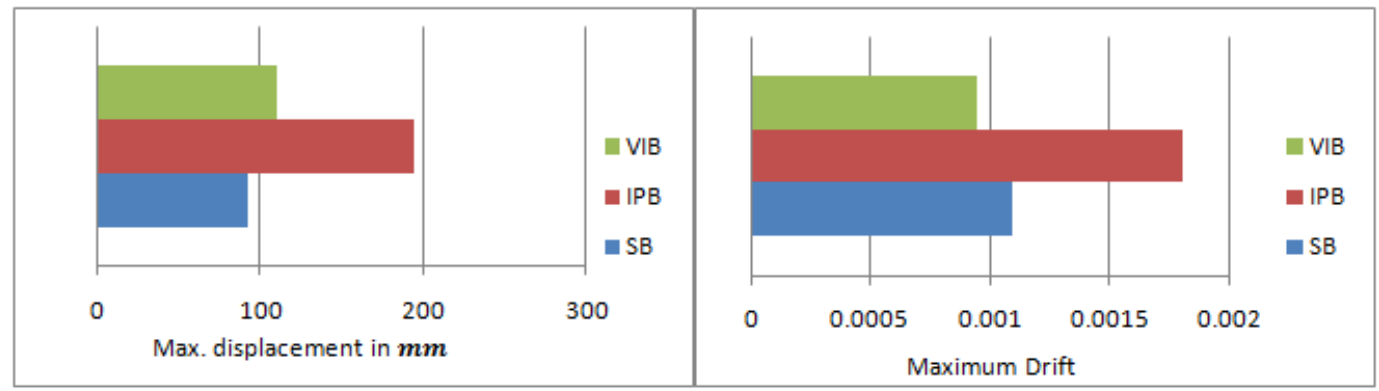

(a)

(b)

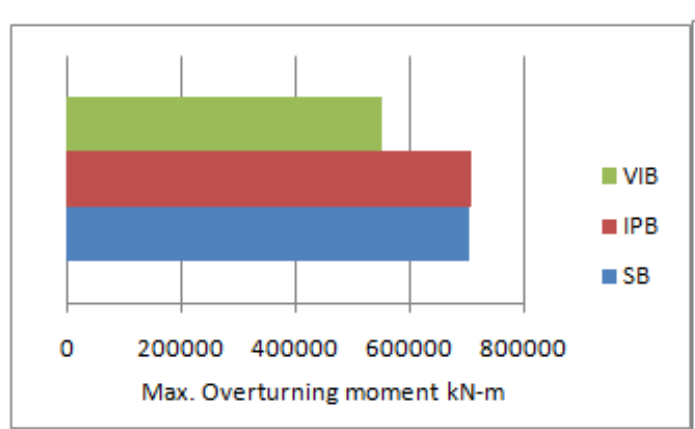

(c)

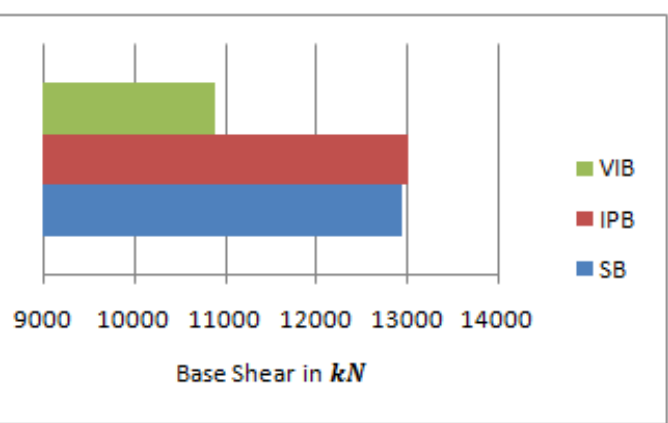

(d)

Figure 9: Shows Variation of (a) Max. Displacement (b) Max. Drift (c) Max. Overturning Moment (d) Max. Base Shear due to Wind Analysis in Terrain Category-3.

\begin{tabular}{|c|c|c|c|c|}
\hline \multicolumn{5}{|c|}{ Table 9: Results of Wind Analysis in Terrain Category 4} \\
\hline Models & $\begin{array}{c}\text { Max. Displacement } \\
\text { in } m m\end{array}$ & Maximum Drift & Max. Overturning Moment $k N-m$ & Base Shear in $k N$ \\
\hline SB-R 1 & 42.29 & 0.000764 & 350550.46 & 6424.1872 \\
\hline IPB-R 2 & 102.826 & 0.001357 & 367882.5203 & 6333.9135 \\
\hline VIB-R 3 & 57.919 & 0.000624 & 284125.4565 & 5339.7721 \\
\hline
\end{tabular}




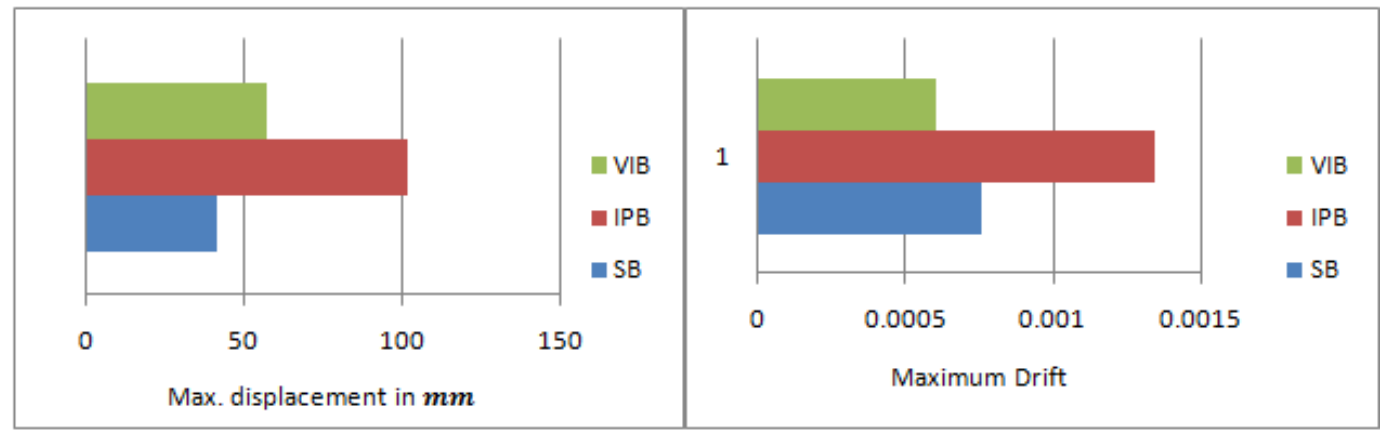

(a)

(b)

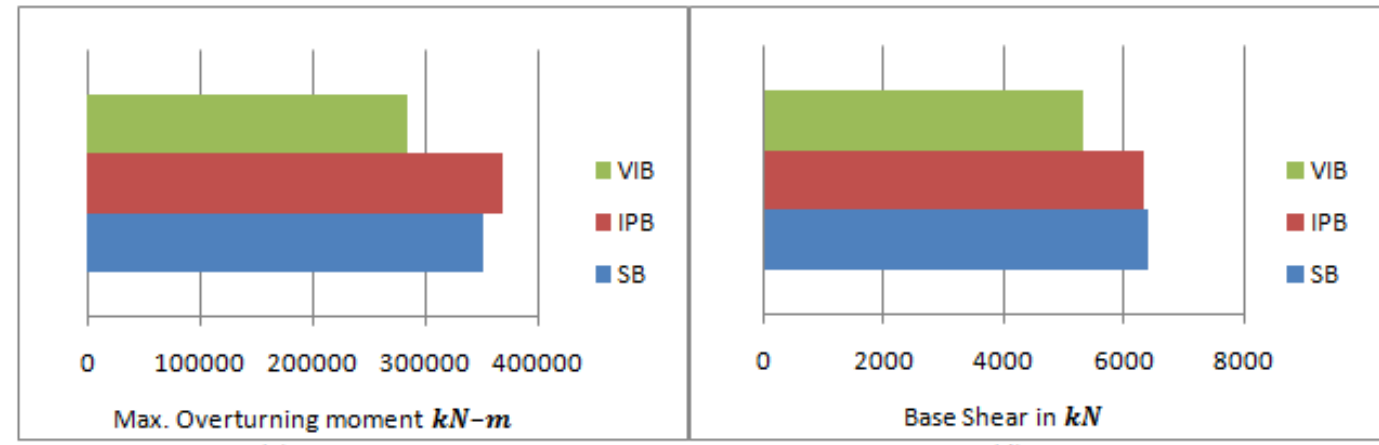

(c)

(d)

Figure 10: Shows Variation of (a) Max. Displacement (b) Max. Drift (c) Max. Overturning Moment (d) Max. Base Shear due to Wind Analysis in Terrain Category-4.

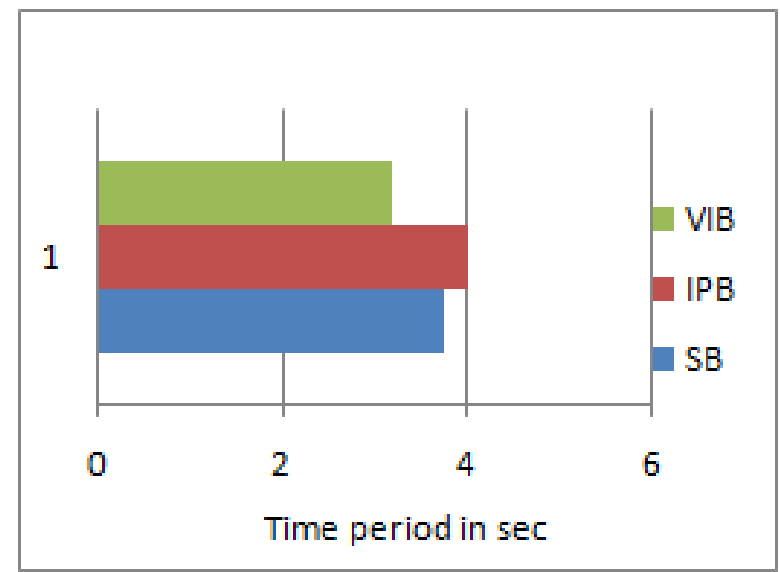

Figure 11: Shows that Time Period of SB-R1 and VIB-R.

\section{CONCLUSIONS}

Comparison of regular and irregular structures in each terrain category was done on the basis of storey displacement, storey drift, storey shear, overturning moment and time period. Following conclusion points are revealed from seismic and wind analysis of G+30 storey buildings.

- The displacement of plan irregular building (PIB-R $)_{1}$ increases with increase of slope angle. In Terrain-3 with slope of ground 20 degrees the displacements of SB- $\mathrm{R}_{1}, \mathrm{IPB}-\mathrm{R}_{2}$ and VIB- $\mathrm{R}_{3}$ are increased $22 \%, 12 \%$ and $49 \%$ as compared to Terrain-1, Terrain2 and Terrain-4.

- Storey drift of SB- $\mathrm{R}_{1}, \mathrm{IPB}-\mathrm{R}_{2}$ and VIB-R $\mathrm{R}_{3}$ in terrain-2 with slope of ground 15 degrees are increased $38 \%, 16 \%$ and $44 \%$ as compared to terrain-1, terrain-3, and terrain- 4 . 
- Over-turning moment also increases with increase of ground slope. In terrain-3 with slope of ground 20 degrees the overturning moment of SB- $\mathrm{R}_{1}, \mathrm{IPB}-\mathrm{R}_{2}$ and VIB- $\mathrm{R}_{3}$ are increased $16 \%, 18 \%$ and $52 \%$ as compared to terrain1 , terrain-2, and terrain-4.

- $\quad$ Base shear of SB-R, IPB-R $\mathrm{R}_{2}$ and VIB- $\mathrm{R}_{3}$, in terrain-3 with ground slope of 20 degrees are increased $19 \%, 12 \%$ and $53 \%$ as compared to terrain-1, terrain-2 and terrain-4.

- $\quad$ Time period is maximum in IPB- $\mathrm{R}_{2}$ and minimum in VIB. Time period of SB- $\mathrm{R}_{1}$ and VIB- $\mathrm{R}_{3}$ is decreased by $9 \%$ and $22 \%$ than IPB- $\mathrm{R}_{2}$ respectively.

- From both the analysis (seismic and wind) it is concluded that vertical irregular building(VIB-R ${ }_{3}$ ) in terrain category-4 with ground slope less than 3 degrees provides greater resistance against both seismic and wind loading among all buildings $\left(\mathrm{SB}-\mathrm{R}_{1}, \mathrm{PIB}-\mathrm{R}_{2}, \mathrm{VIB}-\mathrm{R}_{3}\right)$

\section{REFERENCES}

1. Murty, C. V. R., Goswami, R., Vijayanarayanan, A. R., \& Mehta, V. (2012). Earthquake behaviour of buildings. Gujarat State Disaster Management Authority, Gandhinagar, 53-79.

2. Thapa, Axay, and Sajal Sarkar. "Comparative Study of Multi-Storied RCC Building with and without Shear Wall." International Journal of Civil Engineering (IJCE) Vol 6.

3. Chintanapakdee, C., \& Chopra, A. K. (2004). Seismic response of vertically irregular frames: response history and modal pushover analyses. Journal of Structural Engineering, 130(8), 1177-1185.

4. Valmundsson, E. V., \& Nau, J. M. (1997). Seismic response of building frames with vertical structural irregularities. Journal of Structural Engineering, 123(1), 30-41.

5. Isyumov, N., Fediw, A. A., Colaco, J., \& Banavalkar, P. V. (1992). Performance of a tall building under wind action. Journal of Wind Engineering and Industrial Aerodynamics, 42(1-3), 1053-1064.

6. Moehle, J. P., \& Alarcon, L. F. (1986). Seismic analysis methods for irregular buildings. Journal of Structural Engineering, $112(1), 35-52$.

7. Kwok, K. C. S. (1988). Effect of building shape on wind-induced response of tall building. In Advances in Wind Engineering (pp. 381-390). Elsevier.

8. Shahrooz, B. M., \& Moehle, J. P. (1990). Seismic response and design of setback buildings. Journal of Structural Engineering, $116(5), 1423-1439$.

9. Lavan, O., \& Wilkinson, P. J. (2017). Efficient seismic design of 3D asymmetric and setback RC frame buildings for drift and strain limitation. Journal of Structural Engineering, 143(4), 04016205.

10. Hasan, RaadAbed Al-Jallal. "Behaviour of beam and wall outrigger in high-rise building and their comparison." International Journal of Civil, Structural, Environmental and Infrastructure Engineering Research and Development 6.1 (2016): 19-30.

11. Agrawal, P., \& Shrikhande, M. (2006). Earthquake resistant design of structures. PHI Learning Pvt. Ltd.

12. Raj, R., Sharma, A., \& Chauhan, S. (2018). Response of Square and Plus Shaped Buildings on Varying Wind Loads. Journal of Structural Engineering.

13. Mantha, Vinay, and Sanghai S S. "Comparison between Seismic Analysis and Non-Seismic Analysis of G+ 17 Building Using Sap2000." International Journal of Earthquake Engineering and Geological Science,(IJEEGS) 6.2 (2016). 
14. Munshi, S., \& Bhandiwad, M. S. (2016). Seismic Analysis of Regular and Vertical Irregular RC Buildings. Bonfring International Journal of Man Machine Interface, 4(Special Issue Special Issue on Computer Aided Analysis and Design of Structures| Editors: Dr. D K Kulkarni, Dr. R J Fernandes, Dr. S B Kulkarni), 178-181.

15. Tezcan, S. S., \& Alhan, C. (2001). Parametric analysis of irregular structures under seismic loading according to the new Turkish Earthquake Code. Engineering structures, 23(6), 600-609.

16. Bhoyar, Sanjay, and D. Parbat. "Repetitive project scheduling: developing CPM-like analytical capabilities." International Journal of Civil Engineering 3.5 (2014): 37-46.

17. Sumukam Sai, Charan Raj, Suraj Baraik, Dr. G Venkata Ramana, “wind analysis of high-rise buildings using sap2000”, International Journal of Civil Engineering and Technology (IJCIET) Volume 9, Issue 8, August 2018.

18. Chen, X., \& Kareem, A. (2005). Coupled dynamic analysis and equivalent static wind loads on buildings with threedimensional modes. Journal of structural Engineering, 131(7), 1071-1082.

\section{AUTHORS PROFILE}

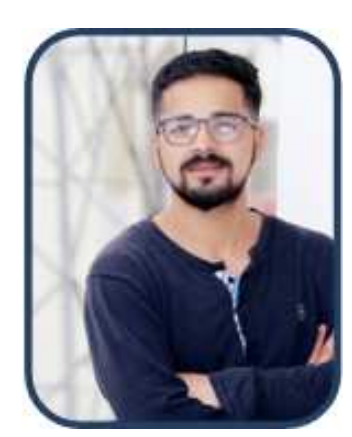

Bilal Ahmad Lone, currently pursuing his Master's degree in Structural Engineering from Chandigarh University (CU), Mohali, Punjab India. He received his Bachelor's degree from Rajiv Gandhi Proudyogiki Vishwavidyalaya, Indore India (University of Technology Of Madhya Pradesh). His area of research interests is Building construction, Design and Analysis, Earthquake Resistant Structures and Industrial Structures.

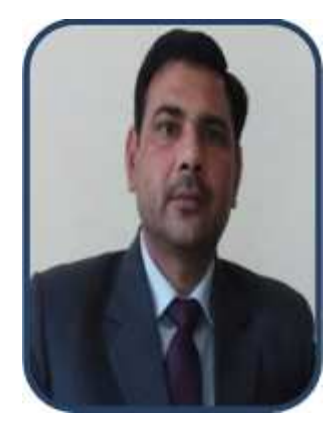

Jagdish Chand holds bachelor's degree in Civil Engineering, master's degree in Structural Engineering and pursuing his Ph.D. degree from National Institute of Technology, Kurukshetra. He is an Associate Professor in UIE-Civil Engineering at Chandigarh University, Mohali. He has more than eighteen years of rich experience spanning across teaching and industrial work. His area of interest includes cementitious materials, high strength concrete, steel concrete composite structures. 


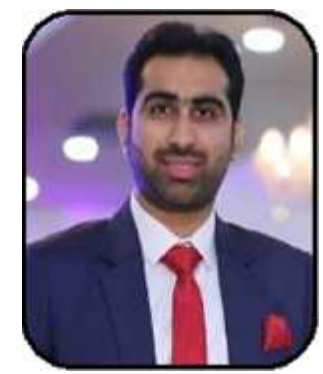

Dr. Mohit Bhandari, Assistant Professor, Department of Civil engineering, Chandigarh University, Mohali, Punjab, India. His area of research is Seismic Analysis of Buildings, Nonlinear Analysis, Base Isolation, Performance Based Design. 